\title{
Investigation on thermodynamics characteristics of biomass thermal decomposition using TG/DSC method
}

\author{
Z.J. TANG ${ }^{1}$ \& P. FANG ${ }^{1}$ \& $\&$ J.H. HUANG ${ }^{1}$ \& Z.X. TANG ${ }^{1}$ \& C.P. CEN ${ }^{1}$ \\ ${ }^{1}$ South China Institute of Environmental Sciences, Ministry of Environmental Protection, \\ Guangzhou, PR China
}

\begin{abstract}
KEYWORD: biomass; DSC analysis; combustion and pyrolysis; thermal decomposition
ABSTRACT: Based on results of biomass combustion and pyrolysis using TG-DSC analyzer, biomass thermodynamics characteristics were studied. Integrated heat model and differential heat model were used to determined biomass thermal behavior, and the former fitted the actual better; the heat capacities with temperature can be empirically expressed in the linear form $\mathrm{c}_{p i} \rightarrow \mathrm{c}_{1}+\mathrm{c}_{2} \times \mathrm{T}_{c}$
\end{abstract}

as: $\quad$ Study results provided an insight of biomass thermal decomposition mechanism.

\section{INTRODUCTION}

As a renewable source, biomass has gained growing interest due to the energy crisis. Thermal processes, i.e. combustion and pyrolysis, are considered as major and particular suitable routes to convert biomass material to energy, along with other degradation methods, such as gasification, anaerobic digestion, alcohol production and so on(Kobayashi, H., 2014; Fang, P., 2015). DSC analysis enables to study samples to different temperature profiles and gaseous environment in a controlled manner for mass and heat measurements (Shen, J.C., 2015). During biomass combustion and pyrolysis, mass loss and reaction heat was a important thermal analysis tools to study the heating behavior.

Thermogravimetry (TG)/differential scanning calorimetry (DSC) analyzer can measure the sample loss and heat flow at the same time with different heating temperature and gaseous environment. TG/DSC method is an important tool to calculate caloric requirement and evaluate the releasing energy during combustion and pyrolysis to investigate whether biomass thermal decomposition is capable to maintain self-energy balance (He, F., 2006).

In this study, DSC method was used to investigate the thermodynamics characteristics of a typical biomass sample during combustion and pyrolysis; integral and differential reaction heats and models were applied; and the heat capacity of biomass in the first stage was studied.

\section{MATERIAL AND METHOD}

\section{Material preparation}

Biomass extrusion material was purchased from a biomass process factory in Guangdong province (PR China), the main raw material of it was sawmilling and sawdust of eucalyptus, which was residue of furniture processing. The biomass extrusion material was milled by a grinding machine (FRITSCH pulverisette 2), and sieved by standard screens to obtain a particle size in the range of $125 \mu \mathrm{m}$ to $150 \mu \mathrm{m}$. The collected powder was put in a Hermetic bag for use in experiments.

\section{Experimental apparatus}

Biomass pyrolysis and combustion experiments were performed in a simultaneous thermal analyzer (NETZCH STA449 F3) with air (for combustion) or nitrogen (for pyrolysis) at the flow rate of $50 \mathrm{ml} / \mathrm{min}$. The biomass samples of $15 \pm 0.5 \mathrm{mg}$ were weighting on an ultramicro analytical balance (Mettler-Toledo, XS3DU XP) and held in 70uL alumina crucible with a lid for the experiments. The experimental temperature ranged from $30^{\circ} \mathrm{C}$ to $700^{\circ} \mathrm{C}$, and the heating rate was controlled at $20^{\circ} \mathrm{C} / \mathrm{min}$. All TG and DSC results in this study were corrected by baseline which obtained from runs with the empty alumina crucible under the same condition to eliminate the system errors. 


\section{Development of reaction heat models}

Biomass combustion and pyrolysis weight loss can be classified into three stages, moisture removal in the first stage; organic content removal in the second stage in which different kinds of hemicellulose and cellulose composited; and fixed carbon content decompose in the last stage, and because of its low fixed carbon content, there is no obvious weight loss during the third stage.

In first and second stages, the heat required or released $\Delta Q(J)$ to any experimental temperature $T$ from basic temperature $\mathrm{T}_{\mathrm{b}}$ is:

$$
\Delta \mathrm{Q}=\mathrm{Q}-\mathrm{Q}_{\mathrm{b}}=\int_{\mathrm{t}_{\mathrm{b}}}^{\mathrm{t}} \mathrm{qdt}
$$

Where $\mathrm{q}$ is the original heat flow at time $\mathrm{t}$ measured by DSC. The corresponding integral reaction heat $\mathrm{H}(\mathrm{J} / \mathrm{g})$

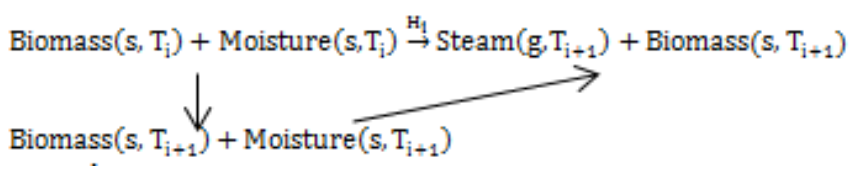
to any experimental temperature can be calculated as:

$$
\mathrm{H}=\frac{\mathrm{Q}-\mathrm{Q}_{\mathrm{b}}}{\mathrm{w}_{\mathrm{b}}-\mathrm{w}}
$$

Where $\mathrm{w}$ and $\mathrm{w}_{\mathrm{b}}$ are the residue and basic sample masses at temperature of $\mathrm{T}$ and $\mathrm{T}_{\mathrm{b}}$ respectively. And the heat $\mathrm{Hr}(\mathrm{J} / \mathrm{g})$ required and released for biomass combustion and pyrolysis can be expressed as:

$$
\mathrm{H}_{r}=\frac{\mathrm{Q}-\mathrm{Q}_{\mathrm{b}}}{\mathrm{w}}
$$

The differential reaction heat $\Delta \mathrm{H}_{\mathrm{i}}(\mathrm{J} / \mathrm{g})$ between temperature $\mathrm{T}_{\mathrm{i}}$ and $\mathrm{T}_{\mathrm{i}-1}$ calculated form the heat of $\mathrm{Q}_{\mathrm{i}}$ and $\mathrm{Q}_{\mathrm{i}+1}$ measured by the DSC is:

$$
\Delta \mathrm{H}_{i}=\frac{\mathrm{Q}_{\mathrm{i}+1}-\mathrm{Q}_{\mathrm{i}}}{\mathrm{w}_{\mathrm{i}}-\mathrm{w}_{\mathrm{i}+1}}
$$

To correlate the integral reaction heats with temperature, it was assumed that the reaction is a function of difference between the reaction temperature and basic temperature:

$$
\mathrm{H}=\sum_{\mathrm{j}=0}^{6} \mathrm{a}_{\mathrm{j}}\left(\mathrm{T}-\mathrm{T}_{\mathrm{b}}\right)^{\mathrm{j}}
$$

Where $\mathrm{a}$ is the fitted constant for the integral reaction heat $\left(\mathrm{J} \cdot \mathrm{g}^{-1} \cdot \mathrm{K}^{-\mathrm{j}}\right)$, the subscript and subscript $\mathrm{j}$ are index of constant $a$, and the power of $T$ respectively. When $T=T_{b}, H=H_{b}=a_{0}$, which is the reaction heat at the basic temperature. And the empirical equation for differential reaction heats:

$$
\Delta \mathrm{H}=\sum_{\mathrm{j}=0}^{6} \mathrm{~b}_{\mathrm{j}}\left(\mathrm{T}-\mathrm{T}_{\mathrm{b}}\right)^{\mathrm{j}}
$$

Where $b$ is the fitted constant for the integral reaction heat $\left(\mathrm{J} \cdot \mathrm{g}^{-1} \cdot \mathrm{K}^{-\mathrm{j}}\right)$, the subscript and subscript $\mathrm{j}$ are index of constant $b$ and the power of $T$ respectively.

\section{Modeling biomass heat capacities during the first stage of combustion and pyrolysis}

The first stage of biomass combustion and pyrolysis is considered as the moisture removal in biomass. Let $\mathrm{w}_{\mathrm{i}}$ represent the sample mass fraction at the temperature of $\mathrm{T}_{\mathrm{i}}$. According to thermodynamics principle, the heat requirement $\mathrm{H}_{\mathrm{i}}$ of $\mathrm{w}_{\mathrm{i}}$ biomass to the temperature $\mathrm{T}_{\mathrm{i}+1}$ from the temperature $\mathrm{T}_{\mathrm{i}}$ can be calculated as the sum of sensible heat requirement $\mathrm{H}_{\mathrm{i} 1}$ of $\mathrm{w}_{\mathrm{i}}$ biomass in increasing its temperature from $T_{i}$ to $T_{i+1}$ and the evaporation heat of moisture $H_{i+1}$ at the temperature $T_{i+1}$ showed as follow:

Then $\mathrm{H}_{\mathrm{i}}=\mathrm{H}_{\mathrm{i} 1}+\mathrm{H}_{\mathrm{i} 2}$,

$\mathrm{H}_{\mathrm{i} 1}=\mathrm{c}_{\mathrm{pw}}\left(\mathrm{wi}-\mathrm{w}_{\text {of }}\right)\left(\mathrm{T}_{\mathrm{i}+1}-\mathrm{T}_{\mathrm{i}}\right)+\mathrm{c}_{\mathrm{pi}} \mathrm{W}_{\text {of }}\left(\mathrm{T}_{\mathrm{i}+1}-\mathrm{T}_{\mathrm{i}}\right)$

Where $\mathrm{c}_{\mathrm{pi}}\left(\mathrm{J} \cdot \mathrm{g}^{-1} \cdot \mathrm{K}^{-1}\right)$ and $\mathrm{c}_{\mathrm{pw}}\left(4.184 \mathrm{~J} \cdot \mathrm{g}^{-1} \cdot \mathrm{K}^{-1}\right)$ are the heat capacity of biomass and water respectively.

The evaporation heat, $\mathrm{H}_{\mathrm{i} 2}$ is:

$\mathrm{H}_{\mathrm{i} 2}=\mathrm{L}_{\mathrm{w}}\left(\mathrm{W}_{\mathrm{i}}-\mathrm{W}_{\mathrm{i}+1}\right)$

Where $\mathrm{L}_{\mathrm{w}}$ is the water evaporation heat $\left(2260 \mathrm{~J} \cdot \mathrm{g}^{-1}\right.$ water $)$, and $\mathrm{w}_{\mathrm{i}}-\mathrm{W}_{\mathrm{i}+1}$ is the removed mass of moisture from $T_{i}$ to $T_{i+1}$, the heat $Q_{i+1}-Q_{i}$ measured by TG/DSC between $T_{i+1}$ and $T_{i}$, then

$\mathrm{Q}_{\mathrm{i}+1}-\mathrm{Q}_{\mathrm{i}}=\mathrm{c}_{\mathrm{pw}}\left(\mathrm{w}_{\mathrm{i}}-\mathrm{W}_{\mathrm{of}}\right)\left(\mathrm{T}_{\mathrm{i}+1}-\mathrm{T}_{\mathrm{i}}\right)+\mathrm{c}_{\mathrm{pi}} \mathrm{W}_{\mathrm{of}}\left(\mathrm{T}_{\mathrm{i}+1}-\mathrm{T}_{\mathrm{i}}\right)+\mathrm{L}_{\mathrm{w}}\left(\mathrm{w}_{\mathrm{i}}-\mathrm{W}_{\mathrm{i}+1}\right)$ 


\section{RESULTS AND DISCUSSION}

\section{Biomass material property}

Elemental analyzer was used to determine the content of $\mathrm{C}, \mathrm{H}, \mathrm{N}, \mathrm{S}$ and $\mathrm{O}$, and proximate analysis of solid biofuels (GB/T 28731-2010)(General Administration of Quality Supervision, 2012) was used to determin the content of moisture, ash, volatile and fixed carbon in biomass material, and calorific value was calculated applying Eq.(11) (Demirbas, A., 1997), all the results were shown as Table 1.

Calorific value $(\mathrm{HHV}, \mathrm{MJ} / \mathrm{kg})=\{33.5[\mathrm{C}]+42.3[\mathrm{H}]-15.4[\mathrm{O}]-14.5[\mathrm{~N}]\} \times 10^{-2}$

Table 1. Ultimate analysis, proximate analysis and calorific value of biomass.

\begin{tabular}{ccccc}
\hline \multicolumn{5}{c}{ Ultimate analysis } \\
\hline $\mathrm{C}(\%)$ & $\mathrm{H}(\%)$ & $\mathrm{N}(\%)$ & $\mathrm{S}(\%)$ & $\mathrm{O}^{\mathrm{d}}(\%)$ \\
\hline 46.11 & 6.10 & 3.72 & $\mathrm{LLD}$ & 43.13 \\
\hline \multicolumn{7}{c}{ Proximate analysis } & & Calorific value \\
Moisture & Ash & Volatile & $\mathrm{FC}$ & $(\mathrm{HHV}, \mathrm{MJ} / \mathrm{kg})$ \\
$(\%)$ & $(\%)$ & $(\%)$ & $(\%)$ & 16.94 \\
\hline 10.21 & 1.34 & 74.17 & 14.28 & \\
\hline
\end{tabular}

* d: by difference; LLD: below the lower detection limit.

\section{TG/DTG of tested biomass material}

Thermogravimetric and derivative thermogravimetric (versus temperature) curves of biomass sample during combustion and pyrolysis are shown in Figure 1. From the TG curves, it can be seen that the sample loss of the biomass sample can be divided into two main stages, which are evaporation of water and de-volatilization of organic contents (including volatile matters and fixed carbon). In the first stage, the mass loss is $6.42 \%$ and $3.63 \%$ during combustion and pyrolysis respectively, because the mass loss value was different, it suggested that the water generated during heating was not just the releasing of free and bound water, and it differed as the gaseous condition different; and in the second stage, $88.70 \%$ and $67.78 \%$ mass were decomposed, thus during combustion, sample decomposed more completely.
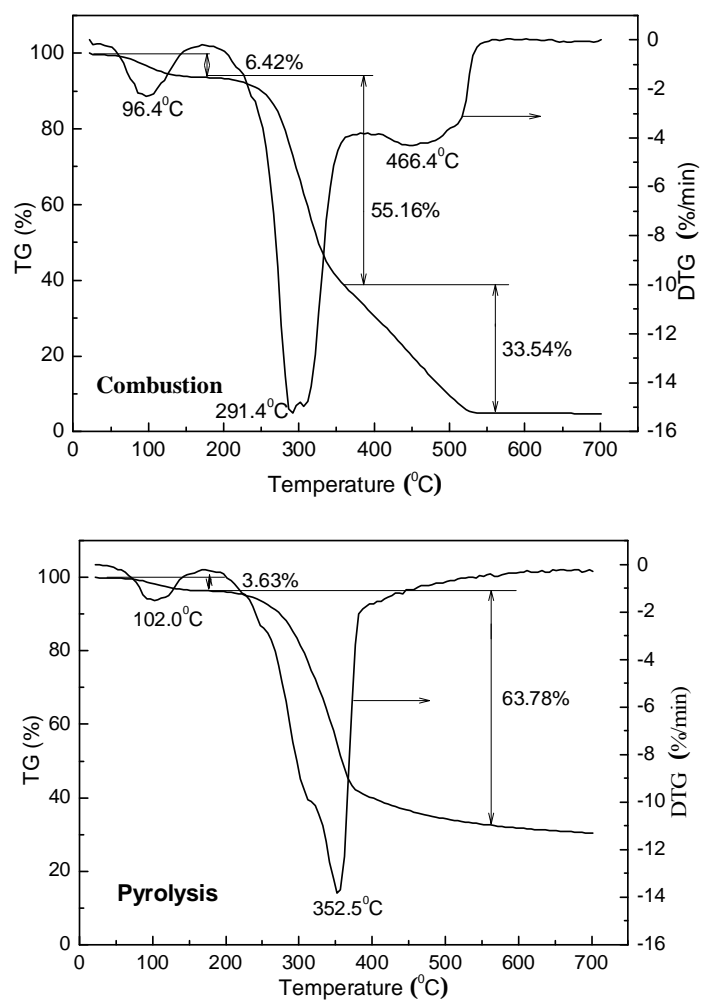

Figure 1. TG and DTG curves of biomass during combustion and pyrolysis. 


\section{Analysis of DSC of tested biomass materials}

Figure 2 is the original heat flow and integrated reaction heat of biomass material during pyrolysis and combustion measured by DSC. The heat flow the biomass material during combustion is endothermic, and the exothermic peak ranged from $100^{\circ} \mathrm{C}$ to $600^{\circ} \mathrm{C}$; while as the heating temperature upgrading, the curve of biomass pyrolysis heat flow was ascending, but with no obvious exothermic peak.

Applying Eq.(1) and Eq.(2), to the curves of the original heat flows with respect to time, the integrated heats $\mathrm{H}$ of combustion and pyrolysis were obtained (Figure 2). The basic integrated heat was $180^{\circ} \mathrm{C}$ to eliminate the contribution of moisture evaporation to the reaction heat. Eq.(5) was used to fit the integrated reaction heat. The integrated reaction model parameters of biomass material during the combustion and pyrolysis were shown in Table 2. It should be notice that the integrated reaction heats calculate through Eq.(5) had a very high fitting degree, the correlation coefficient were both above 0.99 .
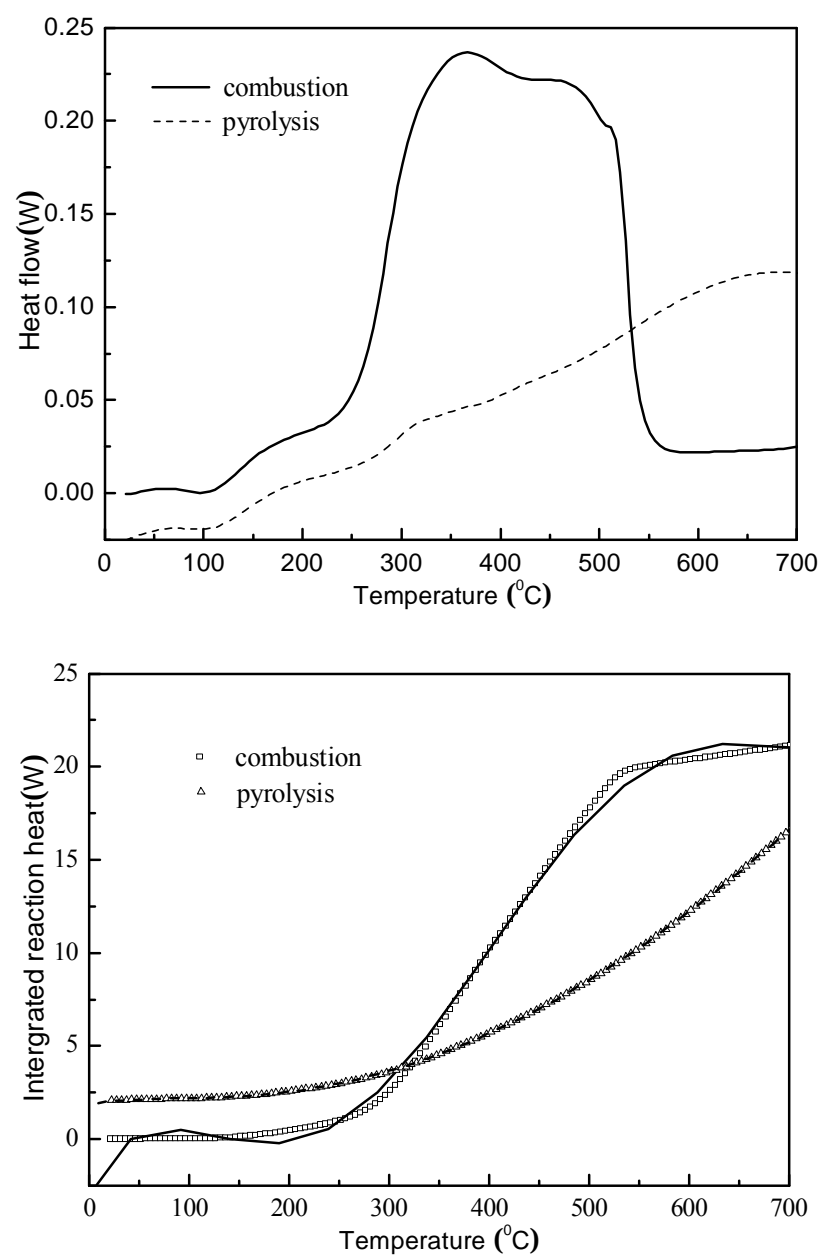

Figure 2. The heat flow and integrated reaction heat during combustion and pyrolysis.

Table 2. Integrated reaction model parameters of biomass during combustion and pyrolysis.

\begin{tabular}{ccccc}
\hline Process & $\mathrm{a}_{0}$ & $\mathrm{a}_{1}$ & $\mathrm{a}_{2}\left(10^{-3}\right)$ & $\mathrm{a}_{3}\left(10^{-6}\right)$ \\
\hline Combustion & 2.681 & 0.103 & 1.110 & 4.584 \\
Pyrolysis & -0.186 & 0.008 & -0.010 & 0.521 \\
\hline Process & $\mathrm{a}_{4}\left(10^{-9}\right)$ & $\mathrm{a}_{5}\left(10^{-12}\right)$ & $\mathrm{a}_{6}\left(10^{-16}\right)$ & $\mathrm{R}^{2}$ \\
\hline Combustion & -7.382 & 4.692 & -7.906 & 0.9979 \\
Pyrolysis & -1.018 & 1.015 & -4.102 & 0.9999 \\
\hline
\end{tabular}

Figure 3 is the differential reaction heat result of the biomass material with respect to mass loss and reaction temperature during the biomass combustion and pyrolysis, and the fitting curves which cal- 
culated from Eq.(4) were obtained, the differential reaction heat mode parameters were shown in Table 3. The correlation coefficient both exceeded 0.9(calculated by Eq.(6)), which means compared to differential reaction heat model, integrated reaction heat model described the reality better.
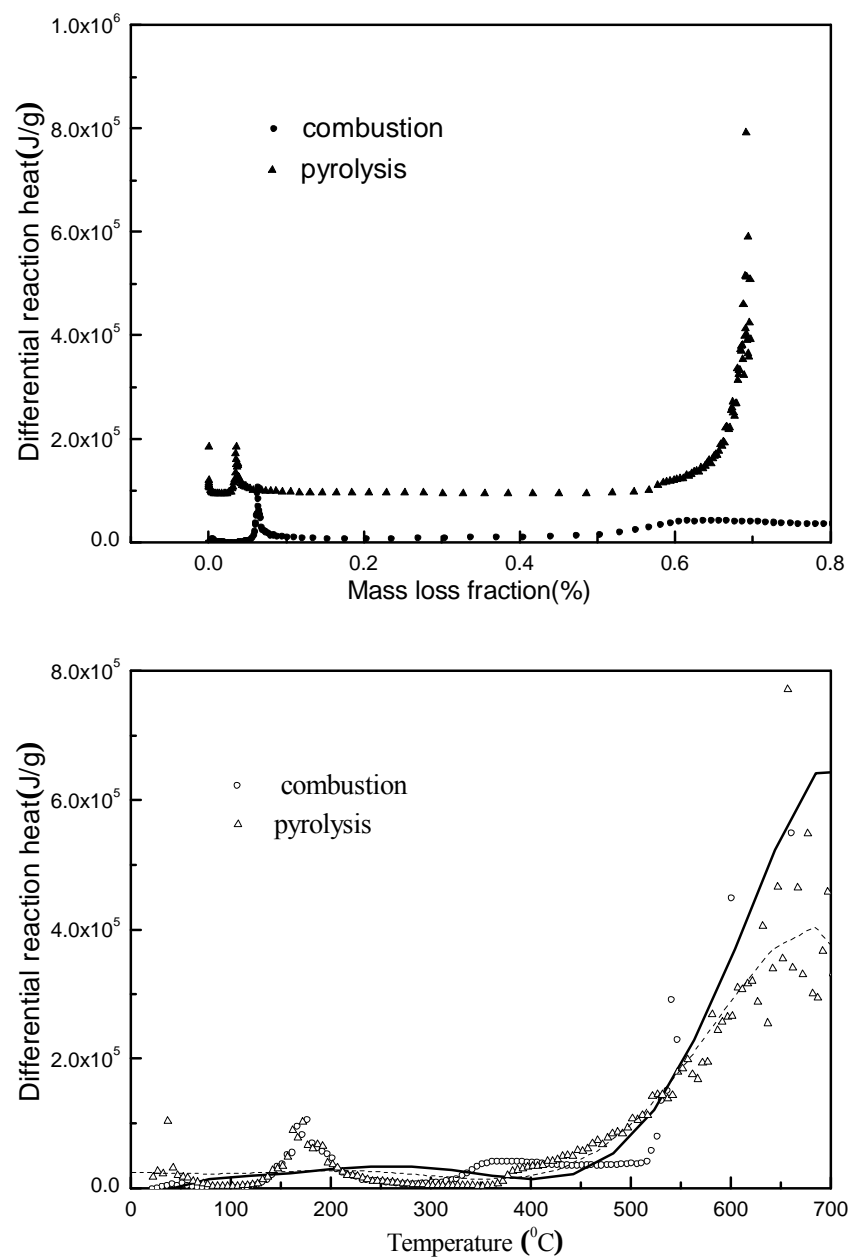

Figure 3. The differential reaction heat with biomass mass loss fraction and temperature.

Table 3. Differential reaction heats model parameters of biomass during combustion and pyrolysis.

\begin{tabular}{ccccc}
\hline Process & $\mathrm{b}_{0}\left(10^{4}\right)$ & $\mathrm{b}_{1}$ & $\mathrm{~b}_{2}$ & $\mathrm{~b}_{3}\left(10^{-2}\right)$ \\
\hline Combustion & -5.070 & $2.022\left(\times 10^{3}\right)$ & -24.595 & 15.167 \\
Pyrolysis & 2.441 & $2.577(\times 10)$ & -1.339 & 2.332 \\
\hline Process & $\mathrm{b}_{4}\left(10^{-4}\right)$ & $\mathrm{b}_{5}\left(10^{-7}\right)$ & $\mathrm{b}_{6}\left(10^{-10}\right)$ & $\mathrm{R}^{2}$ \\
\hline Combustion & -4.674 & 6.738 & -3.545 & 0.8448 \\
Pyrolysis & -1.185 & 2.302 & -1.462 & 08887 \\
\hline
\end{tabular}

\section{Heat capacity with temperature of biomass}

The integrated and differential heats required verses temperatures of the biomass material in the first stage of combustion and pyrolysis were shown in Figure 4.

The heat capacities with temperatures, calculated from Eq.(7) to Eq.(9), of the biomass material for combustion and pyrolysis were shown in Figure 5. Although the heat capacity profiles with temperatures are oscillatory, while the trend of heat capacity for combustion and pyrolysis is increasing with the rising temperature, which is in agreement with observation of other investigation. It is noted that the average heat capacity of biomass in combustion is lower than pyrolysis. It can be attributed to the higher requirement in pyrolysis than in combustion. The heat capacities with temperature can be empirically expressed in the linear form as:

$$
\mathrm{c}_{p i} \rightarrow \mathrm{c}_{1}+\mathrm{c}_{2} \times \mathrm{T}_{c}
$$


Where $\mathrm{c}_{1}\left(\mathrm{~J} \cdot \mathrm{g}^{-1} \cdot \mathrm{K}^{-1}\right)$ and $\mathrm{c}_{2}\left(\mathrm{~J} \cdot \mathrm{g}^{-1} \cdot \mathrm{K}^{-1}\right)$ are the fitting constant, and $\mathrm{T}_{\mathrm{c}}$ is the temperature $\left({ }^{0} \mathrm{C}\right)$. The parameters of Eq.(11) are shown in Table 4 for combustion and pyrolysis. From the Figure 5. it suggested that the pyrolysis fitting degree is better than combustion.
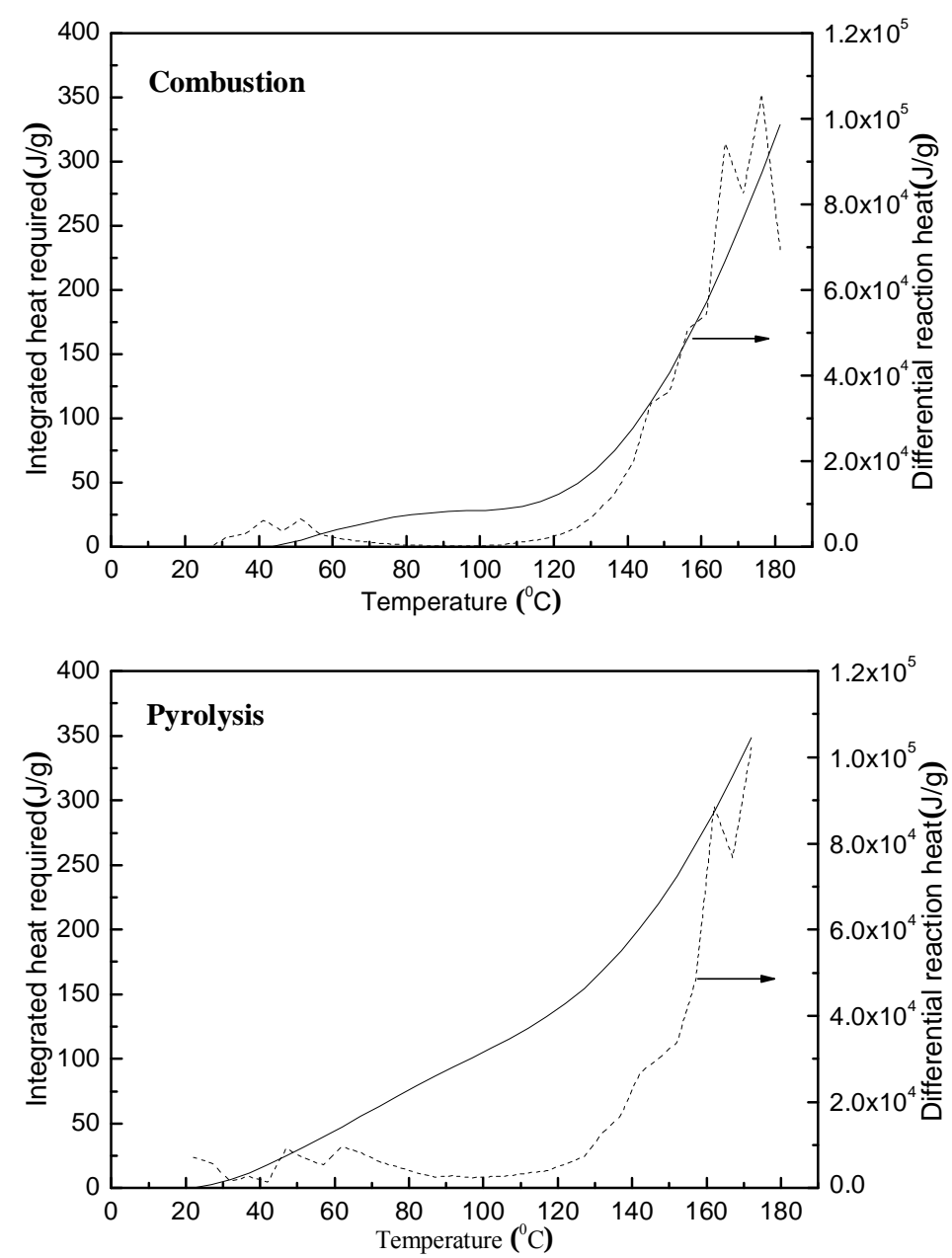

Figure 4. The integrated heat required and differential reaction heat of biomass during combustion and pyrolysis.

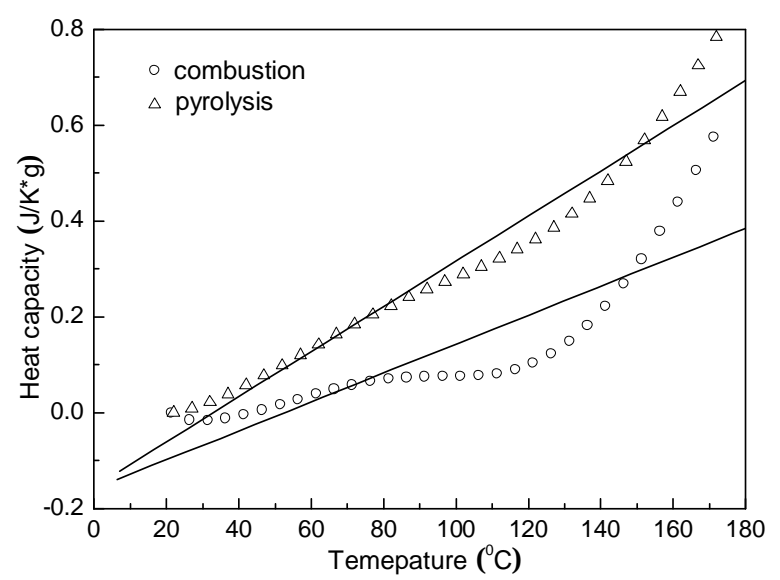

Figure 5. Heat capacity with temperature during combustion and pyrolysis.

Table 4. The heat capacity linear model and parameters.

\begin{tabular}{cccc}
\hline Process & $\mathrm{c}_{1}\left(10^{-1} \cdot \mathrm{J} \cdot \mathrm{g}^{-1} \cdot \mathrm{K}^{-1}\right)$ & $\mathrm{c}_{2}\left(10^{-3} \cdot \mathrm{J} \cdot \mathrm{g}^{-1} \cdot \mathrm{K}^{-1}\right)$ & $\mathrm{R}^{2}$ \\
\hline combustion & -1.58 & 3.02 & 0.7538 \\
Pyrolysis & -1.56 & 4.71 & 0.9594 \\
\hline
\end{tabular}




\section{CONCLUSIONS}

1) Biomass sample mass loss can be divided into water evaporation stage and organic content devolatilization stage; and the biomass material decomposed more completely during combustion than pyrolysis.

2) Biomass kinetics characteristics were studied and key parameters, such as pre-exponential factor and apparent activation energy (E), were determined; linearized reaction model was better used to describe the biomass heating behavior at lower organic decomposition temperature, and was better to apply on pyrolysis than combustion.

3) Integrated heat model and differential heat model were used to determined biomass thermal behavior, and the former fitted the actual better.

4) Heat capacity of biomass in the first stage during combustion and pyrolysis were studied, the heat capacities with temperature can be empirically expressed in the linear form as: $C_{p i} \rightarrow C_{1}+C_{2} \times T_{c}$, and the model was better applied on pyrolysis.

\section{ACKNOWLEDGMENT}

This work was supported by the Project of the Science and Technology Program of Guangdong Province (2014A020216015), and the special funds for research from the environmental charity project (201509013 and PM-ZX021-201407-082)

\section{REFERENCES}

[1] Demirabas, A. 1997. Calculation of Higher heating Value of Biomass Fuels. Fuel, 76(5):431434.

[2] Fang, P., Tang, Z.J., Huang, J.H., Cen, C.P., Tang, Z.X. \& Chen, X.B.. 2015. Using Sewage Sludge as a Denitration Agent and Secondary Fuel in a Cement Plant: A Case Study. Fuel Processing Technology, 137:1-7.

[3] General Administration of Quality Supervision, Inspection and Quarantine of the People's Republic of China, and Standardization Administration of the People's Republic of China. 2012. Proximate Analysis of Solid Biofuels(GB/T 28731-2012). 2012-11-05.

[4] He, F., Yi, W.M. \& Bai, X.Y.. 2006. Investigation on Caloric Requirement of Biomass Prolysis using TG-DSC Analyzer. Enegy Conversion and Management, 47:2461-2469.

[5] Kobayashi, H., Yamakoshi, Y., Hosaka, Y., Yabushita, M., \& Fukuoka, A.. 2014. Production of Sugar Alcohols from Real Biomass by Supported Platinum Catalyst. Catalysis Today, 226:20209.

[6] Shen, J.C., Igathinthane, C., Yu, M.L. \& Pothula, A.K.. 2015. Biomass Pyrolysis and Combustion Integal and Differential Reaction Heats with Temperatures Using Thermogravimetric Analysis/Differential Scanning Calorimetry. Bioresource Technology, 185:998. 